\title{
Atypical Multinucleated Cells Form in Long-term Marrow Cultures from Patients with Paget's Disease
}

\author{
A. Kukita, C. Chenu, L. M. McManus, G. R. Mundy, and G. D. Roodman \\ Research Service and the Geriatric Research, Education and Clinical Center of the Audie Murphy Veterans \\ Administration Hospital and University of Texas Health Science Center, San Antonio, Texas 78284
}

\begin{abstract}
Although Paget's disease is the most flagrant example of a primary osteoclast disorder, little is known of osteoclast biology in this disease. In this report we have studied the formation of cells with the osteoclast phenotype in long-term cultures of marrow mononuclear cells derived from patients with Paget's disease, and compared these with similar cells formed in longterm marrow cultures from normal individuals, and with osteoclasts present in pagetic bone. Osteoclasts formed in pagetic marrow cultures resembled osteoclasts present in pagetic bone, but were distinctly different from osteoclasts formed in normal marrow cultures. Osteoclast formation was 10-20-fold greater in pagetic marrow cultures than in normal cultures. The multinucleated cells formed in cultures of pagetic marrow were much larger in size, were hyperresponsive to $1,25(\mathrm{OH})_{2}$ vitamin $D$, had more nuclei per cell, had increased levels of tartrate-resistant acid phosphatase activity and had ultrastructural features which were not seen in multinucleated cells formed from normal marrow mononuclear cells. These pagetic marrow-derived multinucleated cells formed large resorption lacunae on calcified matrices and cross-reacted with monoclonal antibodies which preferentially bind to osteoclasts. The multinucleated cells formed from marrow obtained from uninvolved sites in Paget's patients also displayed these abnormal features. (J. Clin. Invest. 1990. 85:1280-1286.) osteoclasts • Paget's disease $\cdot$ bone marrow cultures
\end{abstract}

\section{Introduction}

Paget's disease of bone represents the most flagrant example of disordered bone remodeling (1-4) with the primary and fundamental abnormality residing in the osteoclast. This conclusion is based on the following observations: (a) Morphologic studies have demonstrated that abnormal osteoclasts are present in pagetic bone $(5,6)$. These osteoclasts are enormous in size (average number of nuclei 20 , compared with three to four for normal osteoclasts) and have greatly increased numbers of folds in their cytoplasmic membranes, reflecting their abnormally increased surface activity and motility (7). (b) Viral nuclear inclusions, viral antigens and viral transcripts have been reported in these osteoclasts (8-14), suggesting a possible viral etiology for Paget's disease. In contrast, osteoblast morphology

Address reprint requests to Dr. Roodman, Research Service (151), Audie Murphy VA Hospital, 7400 Merton Minter Boulevard, San Antonio, TX 78284.

Received for publication 15 August 1989 and in revised form 15 November 1989.

The Journal of Clinical Investigation, Inc.

Volume 85, April 1990, 1280-1286 appears normal. (c) Treatment of Paget's patients with calcitonin or bisphosphonates, osteoclast-specific agents, reverses the abnormal bone turnover present in this disease (15-17). Although Paget's disease appears to be a primary disease of osteoclasts, little information is available on the functional abnormalities present in pagetic osteoclasts that may be responsible for the enhanced bone turnover seen in these patients.

Since mature osteoclasts from patients with Paget's disease are not readily accessible to study in vitro, we have used longterm human marrow cultures which form multinucleated cells (MNC) ${ }^{1}$ expressing the osteoclast phenotype (18-21) to define the functional abnormalities present in osteoclast precursors from these patients and to characterize the MNC formed in these cultures. Approximately 50\% of the MNC formed in long-term marrow cultures from normal individuals express the following osteoclast characteristics: (a) MNC formation is stimulated by osteotropic hormones such as $1,25(\mathrm{OH})_{2}$ vitamin D and parathyroid hormone (PTH) and is inhibited by calcitonin $(20,21)$. (b) The MNC react strongly with the monoclonal antibody 23c6 developed against human osteoclastoma cells, which preferentially binds to osteoclasts in bone biopsies $(19,22)$. (c) The MNC formed resorption lacunae when cultured on sperm whale dentine (20). (d) The MNC contract in response to calcitonin, a unique feature of mammalian osteoclasts (20). These characteristics distinguish these MNC from the other nonosteoclastic MNC present in marrow cultures.

In this report we demonstrate that the MNC with the osteoclast phenotype formed in cultures of marrow from patients with Paget's disease are distinctly different from MNC with the osteoclast phenotype formed in normal marrow cultures. Further, we report that MNC formation from marrow obtained from uninvolved bone of Paget's patients also displays these abnormal features. These data suggest that either Paget's disease represents a generalized disorder of osteoclasts, or that a systemic factor may be present in patients with Paget's disease that can affect osteoclast precursors in sites not involved with Paget's disease.

\section{Methods}

Materials. $1,25(\mathrm{OH})_{2}$ vitamin D was generously provided by Dr. Uskokovic, Hoffmann-La Roche, Nutley, NJ. Bovine parathyroid hormone (PTH) (1-34) was obtained from Sigma Chemical Co., St. Louis, MO. Salmon calcitonin was obtained from Rorer Pharmaceuticals, Fort Washington, PA. Monoclonal antibodies, 23c6 and 13c2 (22), which preferentially react with osteoclasts, were kindly provided by Dr. Michael Horton (St. Bartholomew's Hospital, London, England). Vectastain ABC-AP kits were purchased from Vector Laboratories,

1. Abbreviation used in this paper: MNC, multinucleated cells. 
Burlingame, CA. Glutaraldehyde, histopaque-1077, and acid phosphatase kits were obtained from Sigma Chemical Co., St. Louis, MO. Alpha-Minimal Essential Medium ( $\alpha$ MEM) was purchased from Gibco Laboratories, Grand Island, NY. Horse serum was obtained from Flow Laboratories, McLean, VA. 24-well multiwell tissue culture plates were obtained from Corning Glass Works, Corning, NY. Lab Tek slides were obtained from Nunc, Inc., Naperville, IL.

Culture of bone marrow cells. After obtaining informed consent, bone marrow was aspirated from the posterior iliac crest of 10 normal subjects and six patients with Paget's disease. Marrow aspirates were taken from areas that were either clinically involved $(n=3)$ or not clinically involved $(n=3)$ with Paget's disease at the time of sampling. The degree of iliac crest involvement had been previously documented by bone scan and $x$-ray techniques. All Paget's patients had elevated serum alkaline phosphatases. Marrow mononuclear cells were obtained by density gradient centrifugation on Hypaque-Ficoll as previously described (20). The cells were washed twice with $\alpha \mathrm{MEM}$ and cultured in $\alpha$ MEM containing $20 \%$ horse serum at $10^{6}$ cells $/ \mathrm{ml}$ in 24-well plates $\left(0.5 \mathrm{ml} /\right.$ well) in the presence or absence of $1,25(\mathrm{OH})_{2}$ vitamin D $\left(10^{-11}-10^{-8} \mathrm{M}\right)$, PTH $(10-100 \mathrm{ng} / \mathrm{ml})$ or calcitonin $(0.1-1$ $\mathrm{U} / \mathrm{ml}$ ). All cultures were maintained in a humidified atmosphere of $4 \%$ $\mathrm{CO}_{2}$-air at $37^{\circ} \mathrm{C}$. Cultures were fed weekly by removing one-half the volume and replacing with fresh media. The normal marrow cultures were maintained for $3 \mathrm{wk}$ and the Paget's marrow cultures were maintained for 2 or $3 \mathrm{wk}$. At the end of the culture period, the cells were fixed in $1 \%$ formaldehyde and then immunocytochemical staining was performed with the $23 \mathrm{c} 6$ monoclonal antibody by using a Vectastain ABC-AP kit as previously described (19). The nuclei were counterstained with $1 \%$ methylgreen. Cells containing three or more nuclei were scored as MNC using inverted phase microscopy.

Determination of tartrate-resistant acid phosphatase activity. Marrow cells from patients with Paget's disease or normals were cultured on Lab Tek slides in the presence of $1,25(\mathrm{OH})_{2}$ vitamin $\mathrm{D}\left(10^{-8} \mathrm{M}\right)$ for $3 \mathrm{wk}$. At the end of the culture period, the cells were fixed and stained for tartrate-resistant acid phosphatase activity as previously described (18). After staining the slides were examined using an image analysis system composed of an Olympus microscope, a Panasonic CCD camera and Cue-2 image analysis software (Dexter Instruments, San Antonio, TX) and the area of the cells determined. The intensity of staining was determined per square micrometer in 100 multinucleated cells from both normal and pagetic marrow cultures, and the mean \pm SEM for absorbance per square micrometer was determined. The percent of light absorbed was calculated by subtracting the percentage of the light transmitted per square micrometer through the cell from $100.100 \%$ light transmission was calibrated on cells that were negative for tartrate resistant acid phosphatase in the same cultures.

Ultrastructural studies. Paget's marrow cells were cultured for 2 or $3 \mathrm{wk}$ and normal marrow cells for $3 \mathrm{wk}$ in the presence of $1,25(\mathrm{OH})_{2}$ vitamin $\mathrm{D}\left(10^{-8} \mathrm{M}\right)$ as described above. The cells were then fixed in a modified Karnovsky's solution containing $1 \%$ paraformaldehyde and $1.5 \%$ glutaraldehyde in $0.1 \mathrm{M}$ of cacodylate buffer $\mathrm{pH} 7.4$ for $90 \mathrm{~min}$ at $4^{\circ} \mathrm{C}$. The cells were subsequently post-fixed in $1 \%$ osmium tetroxide and processed as previously described (18). The sections were then examined for their ultrastructural characteristics using a JEOL $100 \mathrm{CX}$ electron microscope (JEOL USA, Peabody, MA) at an operating voltage of $60 \mathrm{kV}$.

Dentine resorption studies. Bone marrow cells from pagetic patients or normals were cultured in Lab Tek slides for $3 \mathbf{w k}$ in the presence of $1,25(\mathrm{OH})_{2}$ vitamin $\mathrm{D}\left(10^{-8} \mathrm{M}\right)$. For the last week of culture, a small piece of sperm whale dentine was placed over the cultures and the cultures maintained for an additional week. The sperm whale dentine was generously supplied by Dr. Alan Boyde (University College, London, England). After the culture period was completed, the dentine was removed, fixed, and sputtered coated with gold-palladium for scanning electron microscopy as described by Boyde et al. $(23,24)$, except that treatment of the specimens with hexamethyldisilizane for 5 min was used instead of critical point drying.
Statistical analysis. Data was compared by a two-way analysis of variance for repeated measures. Results are reported as the mean \pm SEM for four cultures.

\section{Results}

Multinucleated cell formation in cultures of marrow from patients with Paget's disease after 3 wk of culture was 10-20-fold greater than seen normally in human marrow cultures (Fig. 1). In six separate experiments the number of MNC formed in normal marrow cultures in the absence of osteotropic factors was $51 \pm 28$ (mean \pm SEM) compared to $1,025 \pm 80$ in pagetic marrow cultures. Addition of $1,25(\mathrm{OH})_{2}$ vitamin $\mathrm{D}$ to marrow cultures from patients with Paget's disease markedly enhanced MNC formation in a dose-dependent fashion (Fig. 1). MNC formation was enhanced at $1,25(\mathrm{OH})_{2}$ vitamin D concentrations as low as $10^{-11} \mathrm{M}$. In contrast, normal marrow cultures did not form significant numbers of MNC until $10^{-9} \mathrm{M}$ $1,25(\mathrm{OH})_{2}$ vitamin $\mathrm{D}$ was added to these cultures. MNC formation in the presence of $1,25(\mathrm{OH})_{2}$ vitamin $\mathrm{D}$ was frequently too numerous to count in pagetic marrow cultures containing $10^{-8} \mathrm{M} 1,25(\mathrm{OH})_{2}$ vitamin $\mathrm{D}$, the optimal stimulatory concentration of $1,25(\mathrm{OH})_{2}$ vitamin $\mathrm{D}$ for normal marrow cultures. MNC formation in three separate Paget's marrow cultures containing $10^{-10} \mathrm{M} 1,25(\mathrm{OH})_{2}$ vitamin $\mathrm{D}$ was $2,602 \pm 271$ compared to $438 \pm 122$ in normal marrow cultures containing $10^{-8} \mathrm{M} 1,25(\mathrm{OH})_{2}$ vitamin D. Addition of calcitonin $(1 \mathrm{U} / \mathrm{ml})$ to marrow cultures from Paget's patients significantly decreased MNC formation in the presence of $1,25(\mathrm{OH})_{2}$ vitamin $\mathrm{D}$, (Table I). In addition to $1,25(\mathrm{OH})_{2}$ vitamin $\mathrm{D}$, parathyroid hormone increased MNC formation in cultures of marrow from patients with Paget's disease, although there was no en-

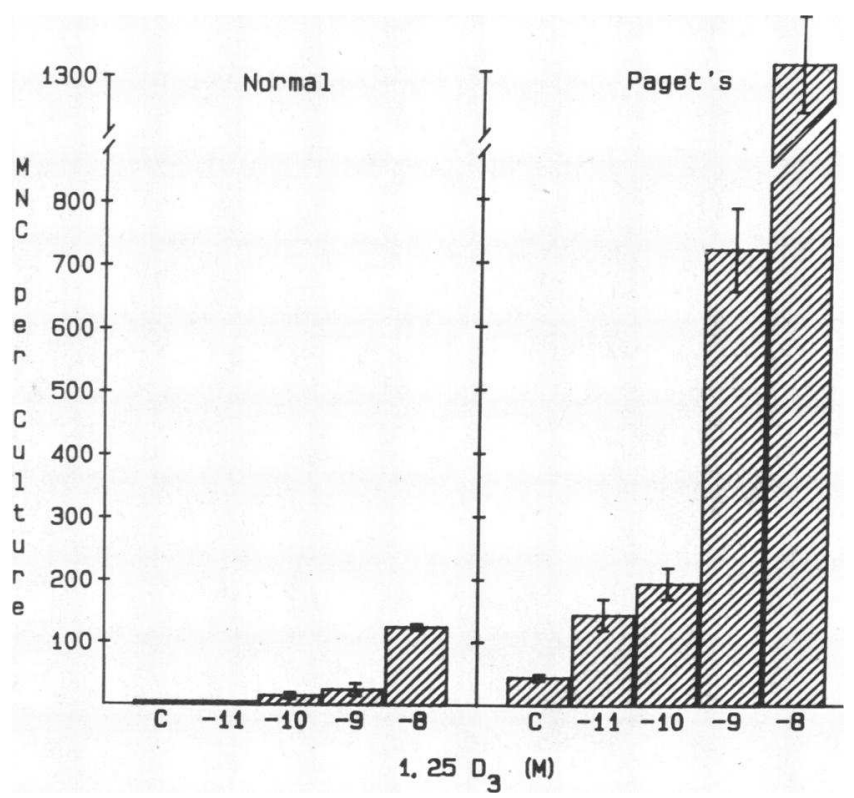

Figure 1. Formation of multinucleated cells in cultures of marrow from a Paget's patient as compared to that from a normal subject. Bone marrow mononuclear cells were prepared as described in Methods and cultured in the presence of $1,25(\mathrm{OH})_{2}$ vitamin $\mathrm{D}$ $\left(10^{-11}-10^{-8} \mathrm{M}\right)$. After $3 \mathrm{wk}$ the number of multinucleated cells were scored. Results represent the mean \pm SEM for four replicate determinations. Similar results were seen in three independent experiments. 
Table I. Effects of Calcitonin on MNC Formation in Marrow Cultures Stimulated by $1,25(\mathrm{OH})_{2}$ Vitamin D or PTH from Paget's Patients

\begin{tabular}{lcc}
\hline \multicolumn{1}{c}{ Treatment } & MNC/Culture & $\begin{array}{c}\text { \% MNC reacting } \\
\text { with 23c6 }\end{array}$ \\
\hline Media & $1,080 \pm 192$ & $87 \pm 1 \%$ \\
$1,25(\mathrm{OH})_{2}$ vitamin D $\left(10^{-10} \mathrm{M}\right)$ & $3,129 \pm 560^{*}$ & $86 \pm 1 \%$ \\
$1,25(\mathrm{OH})_{2}$ vitamin D + Calcitonin & & \\
$(1 \mathrm{U} / \mathrm{ml})$ & $836 \pm 104$ & $91 \pm 1 \%$ \\
PTH $(100 \mathrm{ng} / \mathrm{ml})$ & $2,456 \pm 444^{*}$ & $96 \pm 1 \%$ \\
PTH + Calcitonin $(1 \mathrm{U} / \mathrm{ml})$ & $836 \pm 104$ & $94 \pm 1 \%$ \\
& & \\
\hline
\end{tabular}

* $P<0.05$ compared to media alone.

Bone marrow from patients with Paget's disease was cultured for 2 wk with vehicle, $1,25(\mathrm{OH})_{2}$ vitamin $\mathrm{D}\left(10^{-10} \mathrm{M}\right)$ or PTH $(100$ $\mathrm{ng} / \mathrm{ml})$ in the presence or absence of salmon calcitonin $(1 \mathrm{U} / \mathrm{ml})$. Results are reported as the mean \pm SEM for three or four cultures for a typical experiment. The percentage of MNC reacting with the monoclonal antibody $23 \mathrm{c} 6$, which preferentially identifies osteoclasts is shown in the right hand column. A similar pattern of results was seen in three independent experiments.

hanced sensitivity to PTH. Calcitonin also blocked the effects of parathyroid hormone in these cultures (Table I).

The MNC formed in cultures of pagetic marrow were much larger in size $\left(7,127.8 \pm 739.5\right.$ vs. $\left.2,908.2 \pm 158.5 \mu \mathrm{m}^{2}\right)$ and had more nuclei (4-90 per MNC) than MNC formed in cultures of normal marrow (Fig. 2, Table II). The size and

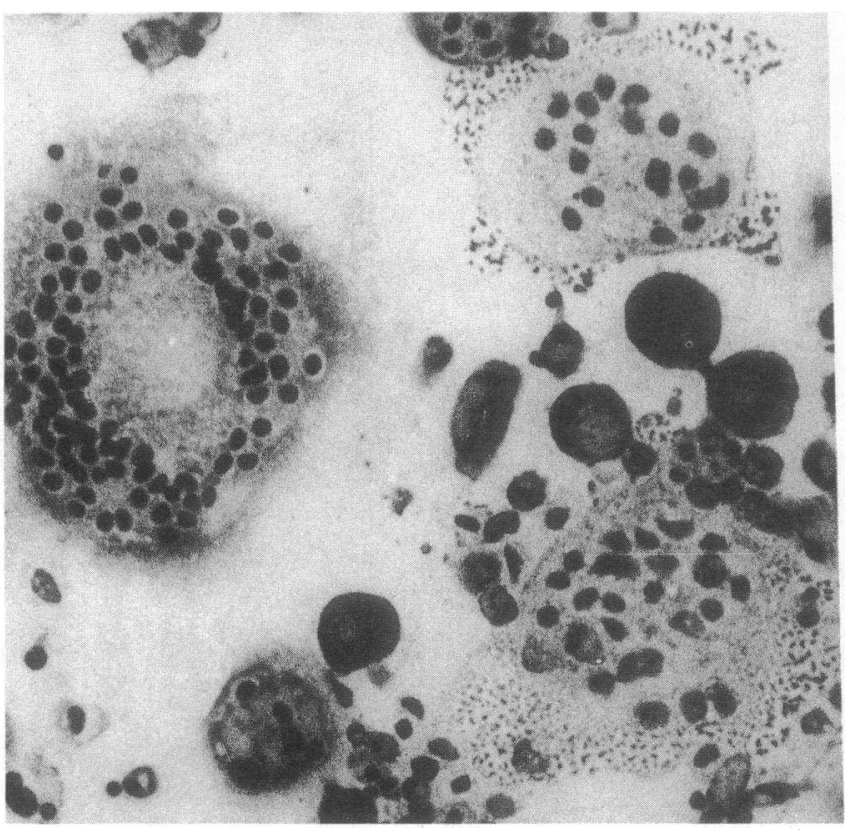

Figure 2. Multinucleated cells formed in Paget's marrow cultures. Bone marrow mononuclear cells from patients with Paget's disease were cultured in the presence of $1,25(\mathrm{OH})_{2}$ vitamin $\mathrm{D}\left(10^{-10} \mathrm{M}\right)$ for $3 \mathrm{wk}$ as described in Methods. At the end of the culture period cells were fixed and stained with Wright's Giemsa stain. Large numbers of MNC formed in these cultures, many of them containing between 4 and 90 nuclei per cell. $\times 250$.
Table II. Nuclear Number and Tartrate Resistant Acid Phosphatase Activity of Osteoclast-like Cells in Long-term Cultures of Marrow from Normals and Paget's Diseased Patients

\begin{tabular}{ccc}
\hline \multicolumn{1}{c}{ Source of marrow } & Nuclei per cell & $\begin{array}{c}\text { TRAP } \\
\text { activity }\end{array}$ \\
\hline $\begin{array}{l}\text { Normal donors }(n=10) \\
\text { Pagetic narrow from } \\
\text { uninvolved sites }(n=3)\end{array}$ & $4.5 \pm 0.04[3-6]$ & $24.8 \pm 8.3$ \\
$\begin{array}{c}\text { Pagetic marrow from } \\
\text { involved sites }(n=3)\end{array}$ & $7.0 \pm 0.50^{*}[3-20]$ & $\mathrm{ND}^{\ddagger}$ \\
\end{tabular}

* $P<0.05$ compared to normal.

$\S P<0.01$ compared to normal.

$¥$ ND, not determined.

Bone marrow from normal donors and patients with Paget's disease was cultured with $1,25(\mathrm{OH})_{2}$ vitamin $\mathrm{D}\left(10^{-8} \mathrm{M}\right)$ for 3 wk as described in Methods. At the end of the culture period, the cells were fixed and stained with Wright's stain to count nuclear number or for tartrate resistant acid phosphatase activity as described in Methods. 100 cells were scored for nuclear number and for TRAP activity. The range for nuclear number is shown in brackets. $n$, number of individual marrow donors. TRAP activity is expressed as the percent of light absorbed per square micrometer, and was calculated by subtracting the percent of light transmitted from $100.100 \%$ light transmission was calibrated on cells which were negative for TRAP activity in the same cultures.

average number of nuclei/MNC were significantly increased in marrow cultures of Paget's patients. This occurred regardless if the marrow was obtained from bone involved or uninvolved with Paget's disease, although the range for nuclear number was not as great in marrow obtained from sites not involved with Paget's disease (Table II). In addition, tartrate- resistant acid phosphatase activity was significantly increased $(P<0.01)$ in MNC formed in pagetic marrow cultures compared to normal (Table II).

The percentage of MNC in marrow cultures from Paget's disease patients that reacted with the monoclonal antibody $23 \mathrm{c} 6$ which identifies osteoclasts was consistently greater than that seen with normal marrow. In cultures treated with $1,25(\mathrm{OH})_{2}$ vitamin $\mathrm{D}\left(10^{-10} \mathrm{M}\right), 71 \pm 7 \%$ (range $60-96 \%$ ) of MNC from Paget's marrow cultures reacted with $23 \mathrm{c} 6 \mathrm{com}-$ pared to $58 \pm 7 \%$ (range $45-60 \%$ ) of MNC from normal marrow cultures. However, because of the large variation from culture to culture, these differences did not achieve statistical significance.

The rate of $\mathrm{MNC}$ formation was also increased in marrow cultures from patients with Paget's disease regardless of whether the marrow was obtained from involved or uninvolved sites. MNC formation in marrow cultures from Paget's diseased patients occurred by the end of the first week of culture, was maximal after $2 \mathrm{wk}$ of culture and declined by $3 \mathrm{wk}$ of culture in the presence of $1,25(\mathrm{OH})_{2}$ vitamin $\mathrm{D}\left(10^{-8} \mathrm{M}\right)$ (Fig. 3). This decrease in MNC formation at $3 \mathrm{wk}$ in the presence of $1,25(\mathrm{OH})_{2}$ vitamin D resulted from a loss of $\mathrm{MNC}$ that detached from the culture plate. In contrast, normal marrow multinucleated cell formation was maximal by 3 wk of culture (Fig. 3). MNC formation in cultures of marrow from patients with Paget's disease in the absence of osteotropic factors was maximal at 3 wk of culture and was similar to the rate of MNC 

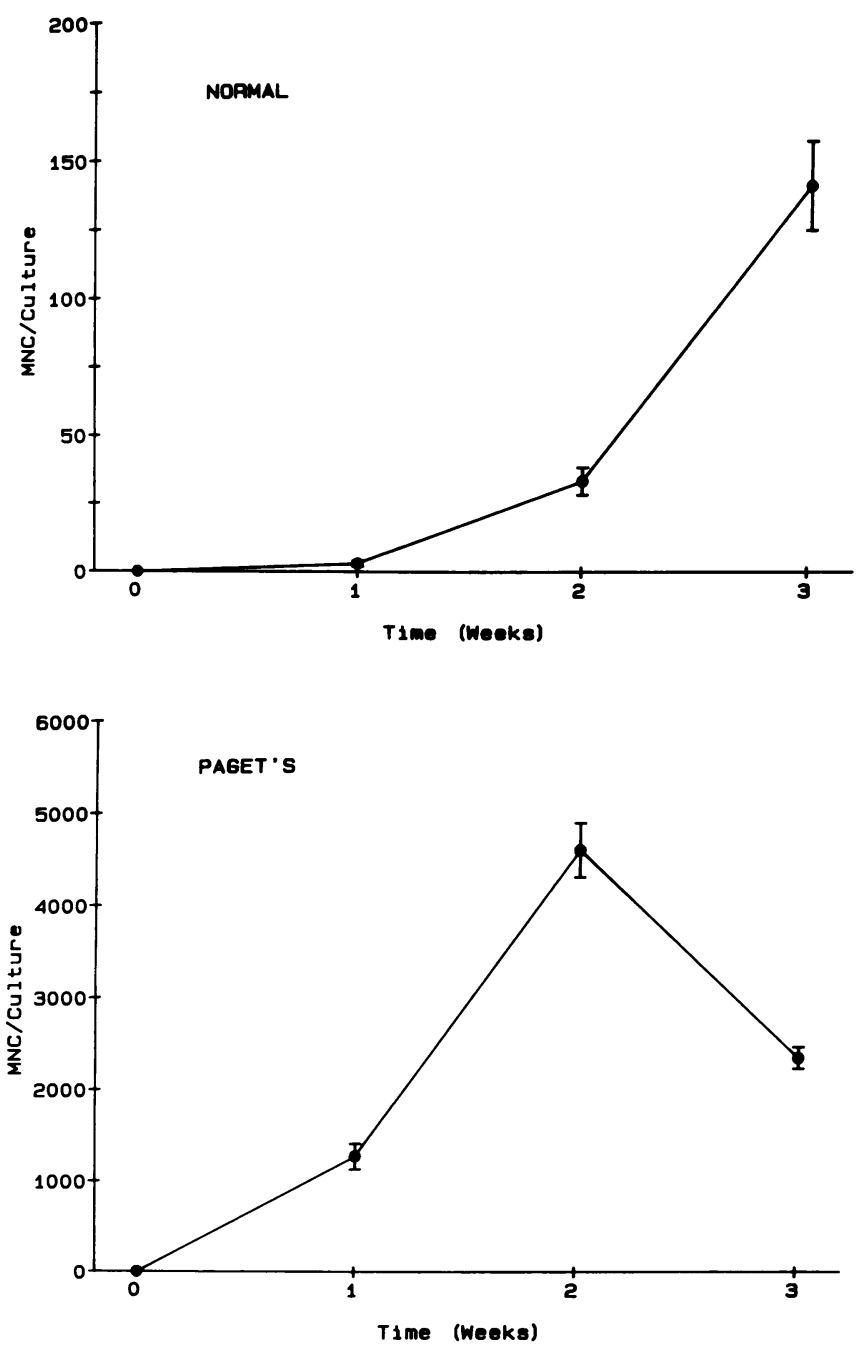

Figure 3. Time course for multinucleated cell formation in Paget's marrow cultures and normal marrow cultures. Bone marrow mononuclear cells were cultured in the presence of $10^{-8} \mathrm{M} 1,25(\mathrm{OH})_{2}$ vitamin D, as described in Methods. At the end of the 1st, 2nd, and 3rd wk of culture, cultures were stopped and the cells fixed and stained with Wright's Giemsa stain. The number of multinucleated cells present in the cultures was then scored. By the $3 \mathrm{rd}$ wk of culture, multinucleated cells were seen floating in the media and appeared to be detaching from the surface of pagetic marrow cultures. Results represent the mean \pm SEM for four determinations. Similar results were seen in three independent experiments. $(A)$ Normal marrow cultures, $(B)$ Paget's marrow cultures.

formation in normal marrow cultures stimulated with osteotropic factors (data not shown).

MNC from pagetic marrow cultures formed resorption lacunae on sperm whale dentine. As seen in Fig. 4, large lacunae were formed by MNC from these cultures.

Ultrastructural studies showed marked differences in the MNC formed in marrow cultures from patients with Paget's disease compared with normal. Overall, MNC from marrow cultures of Paget's patients contain a pattern of intracellular elements that were consistent with a heightened metabolic activity, e.g., increased myelinoid membranes and myelin figures, liposomes, osmiophilic lipid debris, etc. Further, nuclear bodies were present in the nuclei of MNC from marrow cultures obtained from involved sites of Paget's patients (Fig. $5 \mathrm{~B}$ ). No nuclear bodies were seen in normal marrow MNC (Fig. 5 $A$ ). Other cytoplasmic differences between MNC formed from marrow cultures of Paget's patients as compared to those of normal subjects included the presence of centrioles as well as intracellular desmosomes and desmosome-like structures. No ultrastructural differences were observed in marrow cultures obtained from involved sites as compared to uninvolved sites from patients with Paget's disease.

\section{Discussion}

Multinucleated cells formed from marrow cultures obtained from patients with Paget's disease of bone expressed several unique characteristics distinct from MNC formed in normal marrow cultures or normal osteoclasts present in bone. The cells were exquisitely sensitive to $1,25(\mathrm{OH})_{2}$ vitamin $\mathrm{D}$ and responded to concentrations of $1,25(\mathrm{OH})_{2}$ vitamin $\mathrm{D}$ that were 10-100 $\times$ less than those required for normal marrow cells to form MNC. The rate of MNC formation was enhanced in these cultures. Large numbers of MNC formed within the first week of culture of Paget's marrow, whereas few if any MNC formed in normal marrow cultures. In addition, the MNC from Paget's patients contained more nuclei, were much larger than normal MNC, and MNC formation was greatly enhanced in cultures of marrow from Paget's patients compared with normal. Ultrastructurally, the MNC formed in cultures of marrow from Paget's patients differed markedly from those of MNC formed in normal marrow cultures. The cells contained nuclear bodies, had pleomorphic nuclei and had distinct cytoplasmic differences. In addition, a greater percentage of these cells reacted with $23 \mathrm{c} 6$, a monoclonal antibody that identifies osteoclasts. Thus, MNC formed in cultures of marrow from Paget's patients differ from those formed in normal marrow cultures.

Most of the MNC formed in cultures of Paget's marrow expressed the osteoclast phenotype. The cells contained high amounts of tartrate-resistant acid phosphatase, were multinucleated, the majority of MNC (60-96\%) expressed antigens which are preferentially expressed by osteoclasts, and $20 \%$ of the MNC formed resorption lacunae on calcified matrices. In addition, MNC formation was stimulated by osteotropic hormones $1,25(\mathrm{OH})_{2}$ vitamin D and PTH, and the increased formation of these $\mathrm{MNC}$ by $1,25(\mathrm{OH})_{2}$ vitamin D or PTH was inhibited by calcitonin. Taken together, these data suggest that these cells are expressing the osteoclast phenotype.

It is interesting that, MNC formation in marrow obtained from involved and uninvolved sites of patients with Paget's disease was similar. Although the total number of MNC in marrow cultures from uninvolved sites was less than marrow from sites involved with Paget's disease, it still was greatly enhanced (10-20-fold) compared with MNC formation in normal marrow cultures. In addition, marrow obtained from uninvolved sites showed an increased sensitivity to $1,25(\mathrm{OH})_{2}$ vitamin $\mathrm{D}$, similar to that of marrow cultures from involved sites. MNC formed in marrow cultures obtained from sites not involved with Paget's disease also displayed similar ultrastructural abnormalities as those of MNC formed from marrow obtained from involved sites. These data suggest that sites not clinically involved with Paget's disease may either have sub- 

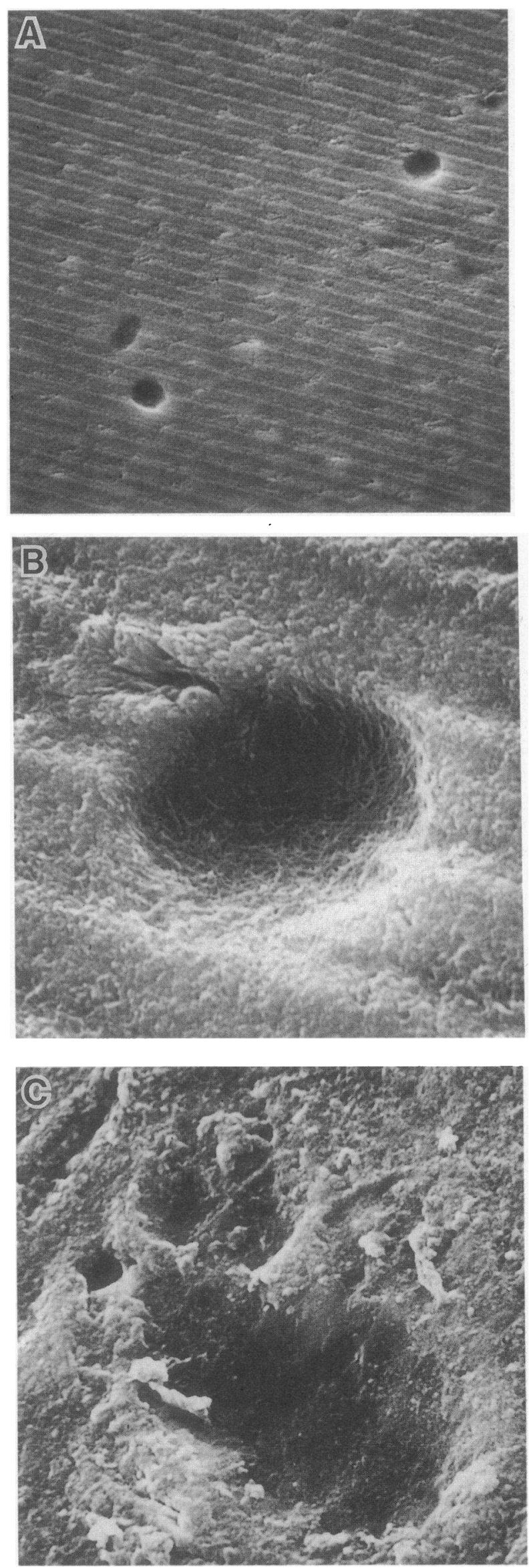

clinical involvement of the pagetic process, or a systemic factor produced by pagetic bone stimulates uncommitted marrow precursors in other sites distant from the lesion to differentiate toward the osteoclast lineage. Consistent with our findings, Meunier et al. (25) have also shown that in $45 \%$ of patients biopsied, bone not clinically involved with Paget's disease also showed increased bone turnover compared to normal bone. Meunier et al. (25) suggested that the increased bone turnover in uninvolved bone in Paget's patients was due to possible hypersecretion of PTH secondary to their increased calcium demand. However, only $12 \%$ of their patients had modestly elevated PTH levels. Similarly, Siris et al. (26) reported that only $18 \%$ of Paget's patients had elevated PTH levels and these increases were only modest. We have examined MNC formed in marrow cultures from a patient with secondary hyperparathyroidism and found that although MNC formation was enhanced (18), the MNC did not express the ultrastructural features seen in Paget's MNC. Thus, other factors in addition to PTH may play a role in the increased osteoclast formation seen in cultures of marrow from uninvolved sites in Paget's diseased patients.

The finding that the rate of $\mathrm{MNC}$ formation was enhanced and the number of nuclei per MNC was increased in pagetic cultures suggests that bone marrow from patients with Paget's disease may have increased numbers of osteoclast precursors which have partially differentiated in vivo. As a consequence, these precursors may fuse more rapidly to form $\mathrm{MNC}$ in vitro. In support of this hypothesis, MNC formation in marrow cultures from patients with Paget's disease was markedly enhanced compared to that in normal marrow. Alternatively, the precursors in Paget's marrow may have an increased propensity to fuse compared to normal marrow precursors.

MNC formed in cultures of marrow from Paget's patients contained nuclear bodies. These nuclear bodies appeared similar to those that have been reported before in highly activated cells $(27,28)$. The nuclear inclusions in the pagetic MNC were not similar to the viral particles that have been reported in pagetic osteoclasts (9-12), since they did not cross-react with viral-specific antibodies against the respiratory syncytial virus or measles virus (data not shown). The increased levels of tartrate-resistant acid phosphatase in these MNC are consistent with these MNC being more activated than MNC from normals.

Our data suggest that Paget's disease affects osteoclast precursors as well as mature osteoclasts. However, we were unable to detect viral material in MNC formed from Paget's marrow. These observations are consistent with ultrastructural studies of pagetic bone. Intranuclear viral inclusions have only been reported in mature osteoclasts and not in mononuclear cells (7-10). Since MNC formed in marrow cultures are formed from mononuclear precursors, we expected that MNC formed in vitro from Paget's marrow might lack viral nuclear inclu-

Figure 4. Resorption lacunae formed by multinucleated cells from normal or pagetic marrow cultures. Bone marrow mononuclear cells were cultured with $1,25(\mathrm{OH})_{2}$ vitamin $\mathrm{D}$ for $2 \mathrm{wk}$, and then a small piece of dentine was added to the cultures. The cultures were continued an additional week with $1,25(\mathrm{OH})_{2}$ vitamin $\mathrm{D}$ and then the dentine scanned for resorption lacunae as described in Methods. $(A)$ Pagetic marrow culture. $\times 650$. (B) Pagetic marrow culture. $\times 5,500$. (C) Normal marrow culture. $\times 5,500$. 

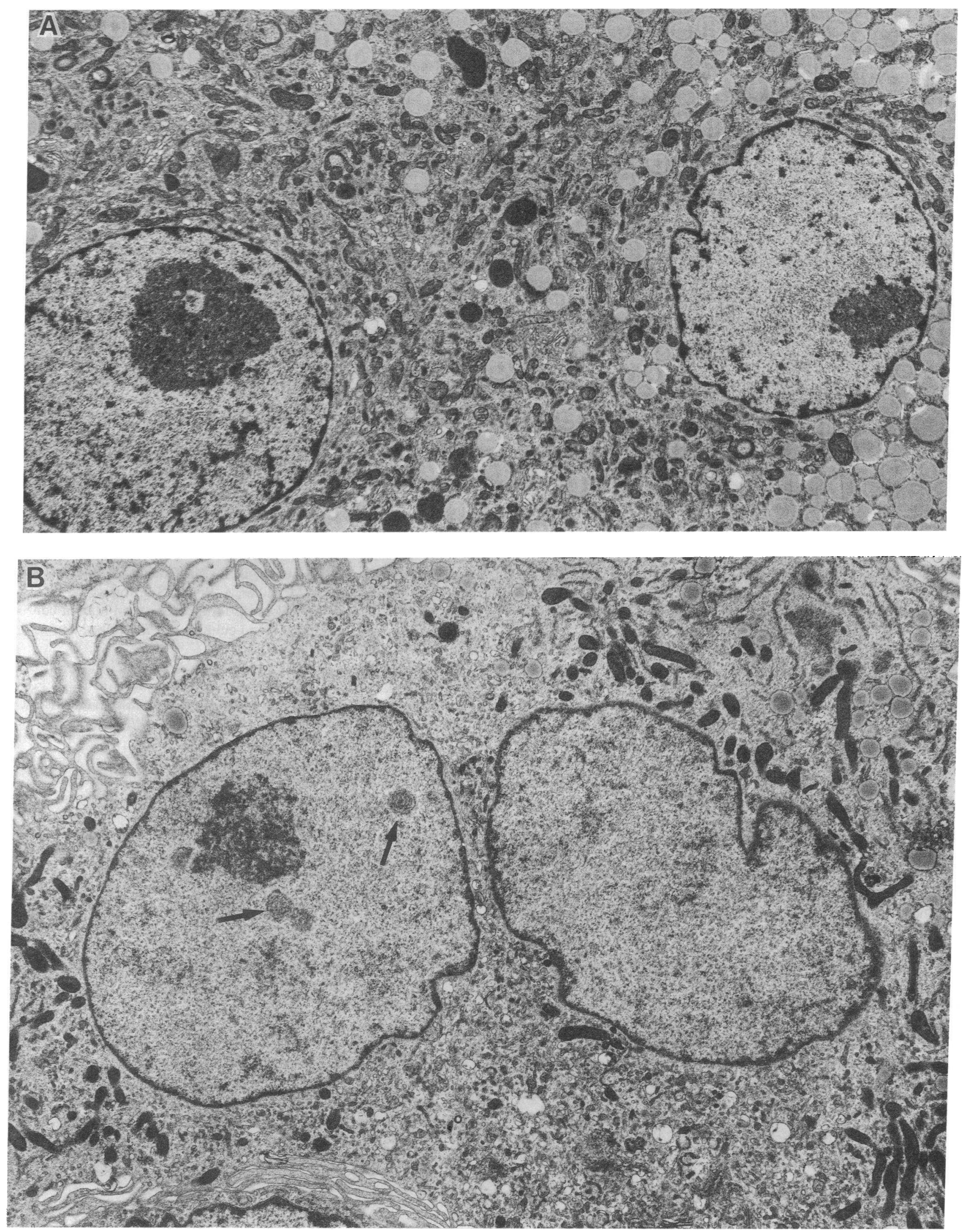

Figure 5. Ultrastructural appearance of representative multinucleated cells formed in normal or pagetic marrow cultures. Bone marrow-derived mononuclear cells were obtained from an active lesion of Paget's disease or from normal marrow and cultured for 2 or 3 wk, respectively, with $10^{-10} \mathrm{M} 1,25(\mathrm{OH})_{2}$ vitamin D. $(A)$ Normal marrow culture. $\times 6,400$. (B) Paget's marrow culture. Several nuclear bodies (arrows) are present. $\times 7,250$. 
sions. Among the possible explanations for these findings are that the viral infection of pagetic osteoclasts is a late event which occurs only in the mature osteoclast and not in its mononuclear precursors, or that the marrow culture conditions we employed were not permissive for expression of the virus.

In conclusion, MNC formed from mononuclear bone marrow precursors from patients with Paget's disease resemble authentic osteoclasts, e.g., multinucleation, tartrate-resistant acid phosphatase activity, appropriate responses to osteotropic factors, resorption of calcified matrices and cross-reactivity with a monoclonal antibody that preferentially binds to osteoclasts. These MNC were distinctly different from MNC formed in normal marrow cultures, but expressed similar features to those reported for pagetic osteoclasts present in bone.

\section{Acknowledgments}

We thank Joye Laderer for typing the manuscript and Margaret Miller for expert technical assistance.

Supported by Research Funds from the Veterans Administration and grant AM-35188 from the National Institutes of Arthritis, Diabetes, and Digestive and Kidney Disease, and grant CA-40035 from the National Cancer Institute. Dr. Roodman is a recipient of a Clinical Investigator Award from the Veterans Administration Research Service.

\section{References}

1. Krane, S. M., and L. S. Simon. 1987. Metabolic consequences of bone turnover in Paget's disease of bone. Clin. Orthop. 217:26-36.

2. Krane, S. M. 1980. Skeletal metabolism in Paget's disease of bone. Arthritis Rheum. 23:1087-1094.

3. Krane, S. M. (1977. Paget's disease of bone. Clin. Orthop. 127:24-36.

4. Cheung, H. S., F. R. Singer, B. Mills, and M. E. Nimni. 1980. In vitro synthesis of normal bone (type I) collagen by bones of Paget's disease patients. Proc. Soc. Exp. Biol. Med. 163:547-552.

5. Gherardi, G. L., V. L. Cascio, and E. Bonucci. 1980. Fine structure of nuclei and cytoplasm of osteoclasts in Paget's disease of bone. Histopathology. 4:63-74.

6. Harvey, L., T. Gray, M. N. C. Beneton, D. L. Douglas, J. A. Kanis, and R. G. G. Russell. 1982. Ultrastructural features of the osteoclasts from Paget's disease of bone in relation to a viral aetiology. J. Clin. Pathol. 35:771-779.

7. Rebel, A., K. Malkani, M. Basle, and C. Bregeon. 1976. Osteoclast ultrastructure in Paget's disease. Calcif. Tissue Res. 20:187-199.

8. Singer, F. R., and B. G. Mills. 1983. Basic Science and Pathology: Evidence for a viral etiology of Paget's disease of bone. Clin. Orthop. 178:245-251.

9. Howatson, A. F., and V. L. Fornasier. 1982. Microfilaments associated with Paget's disease of bone: Comparison with nucleocapsids of measles virus and respiratory syncytial virus. Interivology. 18:150-159.

10. Singer, F. R., and B. R. Mills. 1976. Nuclear inclusions in Paget's disease of bone. Science (Wash. DC). 194:201-202.

11. Basle, M. F., J. G. Fournier, S. Rozenblatt, S. A. Rebel, and M.
Bouteille. 1986. Measles virus RNA detected in Paget's disease bone tissue by in situ hybridization. J. Gen. Virol. 67:907-913.

12. Basle, M. F., W. C. Russell, K. K. A. Goswami, A. Rebel, P. Giraudon, F. Wild, and R. Filmon. 1985. Paramyxovirus antigens in osteoclasts from Paget's bone tissue detected by monoclonal antibodies. J. Gen. Virol. 66:2103-2110.

13. Basle, M. F., A. Rebel, J. G. Fournier, W. C. Russell, and K. Malkani. 1987. On the trail of paramyxoviruses in Paget's disease of bonc. Clin. Orthop. 217:9-15.

14. Rebel, A., M. Basle, A. Pouplard, K. Malkani, R. Filmon, and A. Lepatezour. 1980. Bone tissue in Paget's disease of bone. Arthritis Rheum. 23:1104-1114.

15. Fleisch, H. 1987. Experimental basis for the use of bisphosphonates in Paget's disease of bone. Clin. Orthop. 217:72-78.

16. Basle, M. F., A. Rebel, J. C. Renier, M. Audran, R. Filmon, and K. Malkani. 1984. Bone tissue in Paget's disease treated by ethane-1, hydroxy-1, 1 diphosphonate (EHDP). Clin. Orthop. 184:281-288.

17. Kanis, J. A., and R. E. S. Gray. 1987. Long-term follow-up observations on treatment in Paget's disease of bone. Clin. Orthop. 217:99-125.

18. MacDonald, B. R., N. Takahashi, L. McManus, G. R. Mundy, and G. D. Roodman. 1987. Formation of multinucleated cells which respond to osteotropic hormones in human long-term marrow culture. Endocrinology. 120:2326-2333.

19. Kukita, T., L. M. McManus, M. Miller, C. Civin, and G. D. Roodman. 1989. Osteoclast-like cells formed in long-term human bone marrow cultures express a similar surface phenotype as authentic osteoclasts. Lab. Invest. 60:532-538.

20. Takahashi, N., T. Kukita, B. R. MacDonald, A. Bird, G. R. Mundy, L. M. McManus, M. Miller, A. Boyde, S. J. Jones, and G. D. Roodman. 1989. Osteoclast-like cells form in long term human bone marrow but not in peripheral blood cultures. J. Clin. Invest. 83:543550 .

21. Roodman, G. D., K. J. Ibbotson, B. R. MacDonald, T. J. Kuehl, and G. R. Mundy. 1985. 1,25-Dihydroxyvitamin $D_{3}$ causes formation of multinucleated cells with several osteoclast characteristics in cultures of primate marrow. Proc. Natl. Acad. Sci. USA. 82:82138217.

22. Horton, M. A., D. Lewis, K. McNulty, J. A. S. Pringle, and T. J. Chambers. 1985. Monoclonal antibodies to osteoclastomas (Giant cell bone tumors): definition of osteoclast-specific cellular antigens. Cancer Res. 45:5663-5669.

23. Jones, S. A., A. Boyde, N. N. Ali, and E. Maconnachie. 1986. Variation in the sizes of resorption lacunae made in vitro. Scanning Electron Microsc. 4:1571-1580.

24. Boyde, A., N. N. Ali, S. J. Jones. 1985. Optical and scanning electron microscopy in the single osteoclast resorption assay. Scanning Electron Microsc. 3:1259-1271.

25. Meunier, P. J., J. M. Coindre, C. M. Edouard, and M. E. Arlot. 1980. Bone histomorphometry in Paget's disease. Quantitative and dynamic analysis of Pagetic and nonpagetic bone tissue. Arthritis Rheum. 23:1095-1103.

26. Siris, E. S., T. P. Clemens, D. McMahon, A. Gordon, T. P. Jacobs, and R. E. Canfield. 1989. Parathyroid function in Paget's disease of bone. J. Bone Miner. Res. 4:75-79.

27. Bouteille, M., S. R. Kalifat, and J. Delarue. 1967. Ultrastructural variations of nuclear bodies in human diseases. J. Ultrastruct. Res. 19:474 186.

28. Ghadially, F. N. 1988. Ultrastructural Pathology of the Cell and Matrix. Butterworths, London. 1340. 